\title{
Haste Intramedular Polimérica Bioreabsorvível (PLLA/PHBV) para Uso na Recuperação de Fraturas Ósseas
}

\author{
Betina M. P. Ferreira, Alfredo M. Steffen, Túlio P. Cardoso, Maria do Carmo Alberto-Rincon, Eliana A. R. Duek \\ Centro de Ciências Médicas e Biológicas, PUC
}

Resumo: A crescente utilização de materiais poliméricos bioreabsorvíveis em medicina, tem estimulado pesquisadores na área ortopédica na busca de soluções mais biológicas, substituindo artefatos tais como fios, hastes e placas metálicas por polímeros bioreabsorvíveis no tratamento de fraturas. Para tanto, resolveu-se estudar implantes da blenda de PLLA/PHBV (dois polímeros bioreabsorvíveis) moldados em uma mini-injetora. Esses implantes foram utilizados para recuperação de fraturas de fêmur de coelhos e avaliados em comparação ao fio de Steinmann (aço inox, usado comercialmente). Após eutanásia com 6, 12 e 24 semanas de implantação dos artefatos, os ossos foram estudados com radiografias, exame histológico e ensaio mecânico, enquanto os implantes poliméricos foram submetidos a microscopia eletrônica de varredura (SEM), ensaio mecânico e calorimetria diferencial de varredura modular (MDSC). As radiografias mostraram calos ósseos bem formados, tanto com o uso da haste de polímero como com o controle metálico. O estudo histológico mostrou ausência de reações inflamatórias ou osteólise. O ensaio mecânico mostrou que a consolidação óssea ocorreu nos dois grupos. Tanto no ensaio mecânico como na calorimetria observou-se que a haste polimérica apresentou sinais de degradação progressiva no tempo estudado. Com os dados obtidos neste estudo, podemos afirmar que o implante PLLA/PHBV demonstrou ser efetivo na reparação de fraturas do fêmur de coelhos quando comparado com o controle metálico.

Palavras-chave: PLLA, PHBV, polímeros bioreabsorvíveis, degradação in vivo, osteossíntese de fraturas.

\section{Intramedullary Bioresorbable Polymeric Pin (PLLA/PHBV) for Use in Bone Fracture Recuperation}

\begin{abstract}
The growing interest in medicine with the use of bioreabsorbable polymeric materials has been stimulating researchers from orthopedic area to develop more biological solutions, substituting threads, stems and metallic plates for bioreabsorbable polymers in the treatment of fractures. So, we decided to study implants of the PLLA/PHBV blends (two bioreabsorbable polymers) moulded in a mini-injector. Those implants were used for recovery of fractures of rabbit femur and assessed in comparison with the thread of Steinmann (stainless steel, commercially used). After euthanasia with 6,12 and 24 weeks of implantation of the artifacts, the bones were studied with X ray, histological exam and mechanic test, while the polymeric implants were submitted the scanning electron microscopy (SEM), mechanic test and modular differential scanning calorimetry (MDSC). The X ray showed good calluses bone with the use of the polymer stem as well as with the metallic control. The histological study showed absence of inflammatory reactions or osteolysis. The mechanical test showed bone consolidation in the two groups. In the mechanical test and in the calorimetry studies, the polymeric stem presented signs of progressive degradation within the studied time. With the data obtained, we can state that the implant PLLA/PHBV demonstrated to be as effective in repairing fractures of rabbit femur as the metallic control.
\end{abstract}

Keywords: Bioresorbable polymers, fracture repair, in vivo degradation, PHBV, PLLA.

\section{Introdução}

Nas últimas duas décadas, materiais bioreabsorvíveis têm sido utilizados experimental e clinicamente em procedimentos cirúrgicos ortopédicos, tais como osteossíntese de fraturas, substituição óssea, cartilaginosa e meniscal, e fixação de ligamentos. O uso de compostos de polímeros alia suas diferentes propriedades (mecânicas, térmicas e viscoelásticas) para obter o melhor resultado pretendido nas diversas aplicações ${ }^{[1]}$.

Os polímeros bioreabsorvíveis mais estudados são o poli(ácido láctico) ou PLA, poli(ácido glicólico) ou PGA, poli-p-dioxanona ou PDS, poli(hidroxibutirato) ou PHB e poli(hidroxibutirato)-co-poli(hidroxivalerato) ou PHVB. Todos são substâncias que sofrem degradação principalmente por hidrólise, através da cisão das ligações ésteres, formando grupos terminais carboxila e hidroxila. Os produtos da degradação são incorporados ao ciclo dos ácidos tricarboxílicos e eliminados pelo organismo como dióxido de carbono e água ${ }^{[2]}$. Em função de suas características, são indicados para aplicações em dispositivos ortopédicos ${ }^{[3]}$, suporte para cultura de células ${ }^{[4]}$, tubos para regeneração de nervos $^{[5]}$, além de cartilagens, fígado e intestino ${ }^{[6]}$.

O poli (ácido láctico), ou PLA, é um dos polímeros bioreabsorvíveis aprovados pelo Food and Drug Administration dos EUA para o uso como implantes. Entretanto,

Autor para correspondência: Betina M. P. Ferreira, Laboratório de Biomateriais, Centro de Ciências Médicas e Biológicas, Pontifícia Universidade Católica de São Paulo, Praça Dr. José Ermírio de Moraes, 290, CEP: 18030-230, Sorocaba, SP, Brasil. E-mail: biene_bmp@hotmail.com 
como outros polímeros sintéticos, não tem boa ancoragem e o crescimento das células no mesmo não é satisfatório ${ }^{[7]}$. O homopolímero poli(3-hidroxibutirato) ou PHB e copolímeros randômicos contendo unidades do 3-hidroxibutirato e 3-hidroxivalerato ou PHBV têm sido produzidos em escala industrial, usando bactérias como a Alcaligenes eutrophus ${ }^{[8]}$. Estes biopolímeros disponíveis comercialmente têm atraído muita atenção para o uso em agricultura, marinha e aplicações médicas ${ }^{[8,9]}$. As maiores vantagens destes polímeros termoplásticos são a biocompatibilidade e biodegradabilidade. A degradação do PHBV ocorre tanto in vivo, através da hidrólise da ligação éster, como de forma acelerada no meio ambiente, devido à intervenção de enzimas extracelulares produzidas por microorganismos presentes no solo e na água $^{[8,9]}$.

Os implantes ortopédicos temporários apresentam como característica comum o fato de serem necessários apenas enquanto ocorre a consolidação óssea. Devem ter como propriedades a biocompatibilidade, a resistência mecânica às demandas de estabilização óssea e a bioreabsorção ${ }^{[6]}$. Infelizmente, os biomateriais mais utilizados nas cirurgias ortopédicas ainda são as ligas metálicas ${ }^{[10]}$.

A permanência prolongada dos implantes metálicos no organismo está relacionada a questões como corrosibilidade, imunogenicidade, carcinogenicidade e alteração da fisiologia óssea ou stress shielding. Em virtude desses aspectos, alguns grupos sugerem uma segunda intervenção cirúrgica para a sua remoção, aumentando custos e riscos ao paciente ${ }^{[10]}$. Além disso, re-fraturas e infecções são fatos relativamente freqüentes no tratamento de fraturas de ossos longos ${ }^{[1]}$.

Entre outros problemas na consolidação das fraturas ósseas deve-se considerar o método de imobilização ou fixação. Ao se utilizar fixação rígida com implantes metálicos o osso torna-se menos resistente após a consolidação. A fim de se evitar a atrofia óssea, têm sido desenvolvidos materiais e implantes de fixação semi-rígidos. Assim, o implante de fixação ideal perderia sua resistência gradualmente, transferindo o esforço mecânico que lhe é inerente, para o foco fraturário. Quando o implante não se faz mais necessário pode, então, ser absorvido pelo organismo ${ }^{[10,12]}$. A principal desvantagem atual do uso desses implantes reside na sua inferioridade mecânica, quando comparados com seus similares metálicos ${ }^{[10]}$.

$\mathrm{O}$ uso de artefatos absorvíveis elimina a necessidade de uma segunda cirurgia após a reparação óssea. O implante polimérico deve ter estruturas química e física apropriadas para satisfazer o tempo de vida útil desejável no organismo; ausência de substâncias contaminantes e possibilidade de ser esterilizada, além da degradabilidade controlada pelos fluídos corpóreos ${ }^{[6,13-16]}$. Os polímeros não devem induzir a formação de tumores, trombose ou inflamação nos tecidos vizinhos. Todos estes requisitos reduzem em muito o número de polímeros que são candidatos potenciais para aplicações biomédicas ${ }^{[6,15]}$.

Com a crescente necessidade de materiais que possam ser usados na área médica, resolveu-se estudar uma nova mistura, utilizando dois polímeros bioabsorvíveis, o PLLA e o PHBV. Em estudos anteriores Ferreira e colaboradores mostraram a degradação da mistura PLLA/PHBV in vitro em diferentes composições ${ }^{[17,18]}$. Segundo os autores, a mistura PLLA/PHBV degradou mais lentamente que o PLLA isoladamente, e este por sua vez degradou mais rápido que o PHBV (estudado através de análises térmicas e morfológicas). Dessa forma, optou-se pela mistura PLLA/PHBV 60/40 com propriedades iniciais próximas ao PLLA, já usado comercialmente in vivo. Porém, quando implantada, não se mostrou eficiente para este estudo, pois não suportou o esforço mecânico vs. degradação exigido na fixação de uma fratura de fêmur de coelhos. Com isso escolheu-se a mistura 40/60 PLLA/PHBV, com maior proporção de PHBV, a qual também degradou, porém demonstrou manter por mais tempo suas propriedades in vivo e exerceu satisfatoriamente a sua função de haste intramedular na consolidação das fraturas.

\section{Experimental}

Os polímeros utilizados neste trabalho foram o poli (L-ácido láctico)-PLLA de massa molar $\mathrm{Mw}=100.000 \mathrm{~g} \cdot \mathrm{mol}^{-1}$ (Medisorb - Dupont) e o poli (3-hidroxibutirato-co-3-hidroxivalerato)PHBV, com teor de $12 \%$ de hidroxivalerato (Aldrich), $\mathrm{Mw}=240.000 \mathrm{~g} \cdot \mathrm{mol}^{-1}$.

As misturas de PLLA/PHBV foram obtidas por fusão na composição 40/60 utilizando uma mini injetora Mini Max Molder modelo $L M M$ - 2017, e um molde com dimensões internas de $4 \mathrm{~cm}$ de diâmetro e $6 \mathrm{~cm}$ de comprimento. As amostras foram colocadas dentro do compartimento da mini injetora, aquecidas a $200{ }^{\circ} \mathrm{C}$, cisalhadas e injetadas no molde envolto por uma camisa para mantê-lo aquecido a $120{ }^{\circ} \mathrm{C}$. Após esse procedimento as amostras foram deixadas no molde para esfriar a temperatura ambiente. Depois de retirado do molde as hastes foram armazenadas sob vácuo.

Foram utilizados 36 coelhos Nova Zelândia (6 por grupo), brancos, de ambos os sexos, com idade média de três meses e 2,5 a 3 quilogramas de peso corporal. Esses animais permaneceram em gaiolas recebendo ração comercial e água ad libitum, durante todo o período pós-operatório. As amostras do polímero foram esterilizadas com óxido de etileno e todo o material cirúrgico foi esterilizado em estufa a $120{ }^{\circ} \mathrm{C}$.

Após jejum de doze horas, os coelhos foram submetidos à anestesia com $30 \mathrm{mg} / \mathrm{kg}$ de Cloridrato de Cetamina e $4 \mathrm{mg} / \mathrm{kg}$ de Xilazina por via intramuscular. Feita a tricotomia, procedeu-se à lavagem do membro inferior com solução antisséptica de Clorexidina, seguida de assepsia com Solução Iodada e antissepsia com campos estéreis. Foi realizada incisão longitudinal parapatelar medial, com $5 \mathrm{~cm}$ de extensão, divulsão dos planos subcutâneo, capsulotomia parapatelar medial e deslocamento da patela lateralmente expondo a articulação do joelho. Uma perfuração de 4,5 mm de diâmetro foi realizada no espaço intercondilar do fêmur distal até o canal medular. Realizou-se osteotomia transversa do terço médio da diáfise femoral com o uso de serra manual. Para fixação 
intramedular das osteotomias, no grupo de coelhos dito Grupo Polímero, foi implantada a haste 40/60 de PLLA/PHBV e no outro, dito Grupo Controle, implantou-se a haste de aço inox ("fio de Steinmann"), ambos com diâmetro de 4,0 mm. Após o implante os animais receberam dose única intramuscular de $30 \mathrm{mg} / \mathrm{kg}$ do antibiótico Ampicilina e foram isolados em gaiolas individuais sem qualquer forma de imobilização. Os animais foram submetidos a eutanásia após 6,12 e 24 semanas da cirurgia. Parte do material foi descalcificado e analisado através da análise histológica (osso e tecidos adjacentes), outra parte foi analisada através de radiografias e ensaio mecânico no módulo flexão. Os implantes poliméricos foram caracterizados através de microscopia eletrônica de varredura (SEM), calorimetria diferencial de varredura modular (MDSC) e também através de ensaio mecânico no módulo flexão.

\section{Processamento do material para análise histológica}

Após o sacrifício do animal o fêmur é retirado e colocado em uma solução de Bouin para fixação do material para exame histológico. Depois de 24 horas realizou-se a descalcificação em uma solução de $10 \%$ de ácido nítrico $+10 \%$ de formol, durante aproximadamente um mês. Após fixação, foram lavados em água destilada, desidratados em gradiente crescente de etanol, diafanizadas em xilol e embebidos em parafina (Histosec - Merck). As amostras foram então seccionadas em micrótomo com uma espessura de $4 \mu \mathrm{m}$, prosseguindo-se com a coloração por Hematoxilina de Harris e Eosina (HE) e Tricrômico de Masson. As amostras foram observadas em fotomicroscópio Nikon Eclipse E800. As áreas de interesse, onde foi observada a interação polímero/tecido, foram fotografadas e os negativos ampliados.

\section{Processamento do material para ensaio mecânico}

Para o ensaio mecânico, o fêmur foi submerso em solução fisiológica de cloreto de sódio 0,9\% e armazenado em freezer até o dia anterior ao ensaio. O ensaio mecânico foi no módulo flexão de três pontos, segundo a norma ASTM D 790-95a, em uma MTS TestStar II, utilizando uma célula de carga de $100 \mathrm{kgf}$, a uma velocidade de $1,3 \mathrm{~mm} / \mathrm{min}$. A distância entre as duas extremidades foi de $50 \mathrm{~mm}$. Para os implantes poliméricos, a distância entre as extremidades foi de $18 \mathrm{~mm}$. Os ensaios foram realizados a uma temperatura média de $25^{\circ} \mathrm{C}$ e $50 \%$ de umidade.

\section{Microscopia eletrônica de varredura (SEM) - somente para os implantes poliméricos}

Para avaliar a degradação da blenda PLLA/PHBV, foram realizados estudos iniciais observando a degradação in vitro. A degradação in vitro foi realizada utilizando uma solução tampão fosfato, onde a haste foi submersa e avaliada sua degradação, de tempos em tempos ${ }^{[17,18]}$.

Amostras da superfície da fratura das hastes poliméricas (fraturados em $\mathrm{N}_{2}$ líquido e recobertos com ouro, utilizando-se um metalizador de amostras Sputer Coater BAL-TEC
SCD 050), foram observadas ao microscópio eletrônico de varredura JEOL JXA 840A, utilizando tensão de 10 a $20 \mathrm{kV}$.

\section{Calorimetria diferencial de varredura modular (MDSC) - somente para os implantes poliméricos}

A análise de calorimetria diferencial de varredura modular (MDSC) foi realizada utilizando-se um equipamento de DSC modulado modelo 2920 da TA Instruments Thermal Analysis, a uma taxa de aquecimento de $10{ }^{\circ} \mathrm{C} / \mathrm{min}$ para o primeiro aquecimento e $5^{\circ} \mathrm{C} / \mathrm{min}$ para o segundo aquecimento, ambos modulados $\mathrm{a}+/-0,5{ }^{\circ} \mathrm{C}$ a cada 60 segundos. As amostras foram primeiramente aquecidas de 25 a $210{ }^{\circ} \mathrm{C}$ e mantidas a esta temperatura por 5 minutos até fusão completa, eliminando a história térmica da amostra. Em seguida, as amostras foram resfriadas até $-30{ }^{\circ} \mathrm{C}$ novamente por 5 minutos e aquecidas até $215^{\circ} \mathrm{C}$.

\section{Resultados e Discussão}

\section{Observação clínica}

Foram realizadas osteotomias (cortes) transversas do terço médio do fêmur. A fixação intramedular, como popularizado por Küntscher, fundamenta-se na colocação de haste intramedular justa, fazendo íntimo contato na região do estreitamento do canal femoral (istmo). Um dos princípios para que ocorra a consolidação é ter contato ósseo de pelo menos $50 \%$ entre os dois fragmentos ${ }^{[19]}$.

No pós-operatório observou-se marcha precoce em coelhos tanto do grupo controle quanto do grupo polímero. $\mathrm{Na}$ primeira quinzena pós-operatória todos os animais apresentaram marcha antálgica (de dor) evitando o contato da pata posterior do lado operado com o fundo da gaiola. O retorno à atividade funcional normal ocorreu, em média, a partir da quarta semana pós-operatória, com apoio plantar completo. Em torno de oito semanas, após a cirurgia, foi observado em alguns coelhos, tanto do grupo controle quanto do grupo polímero, o posicionamento ortostático (erétil) sustentado somente nos membros posteriores, demonstrando que estes coelhos obtiveram boa reabilitação funcional. $\mathrm{O}$ posicionamento do membro operado foi satisfatório, não ocorrendo encurtamento longitudinal e/ou rotação no foco fraturário de grau maior que o aceitável, ou seja, até $25^{\circ}$ de desvio angular ou rotacional.

\section{Observação radiológica}

A observação macroscópica não revelou sinais de infecção. A consolidação óssea foi verificada através da formação de calo. Não houve presença de complicações adicionais como degeneração articular, lise (morte) ou necrose óssea (Figuras 1, 2 e 3).

A Figura 1 mostra a formação do calo ósseo após 6 semanas de implante polimérico e do fio de Steinmann (controle). Pode-se observar que o calo ósseo formado na amostra com polímero apresenta grandes dimensões (calo hipertrófico). 


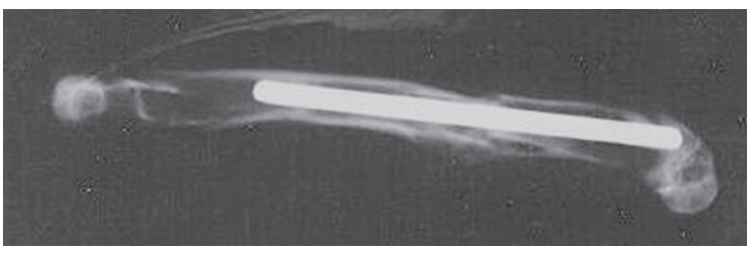

(a)

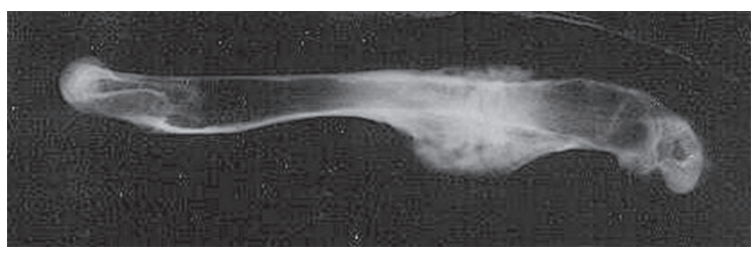

(b)

Figura 1. Radiografias dos ossos com 6 semanas de implante, a) controle Fio de "Steinmann"; e b) blenda 40/60.

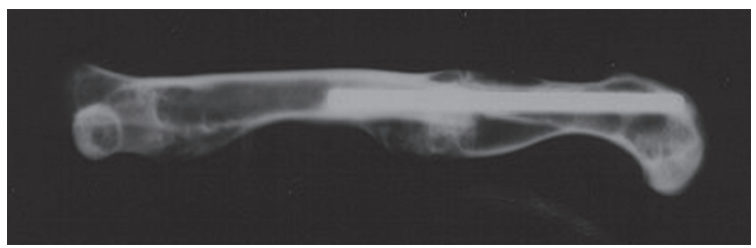

(a)

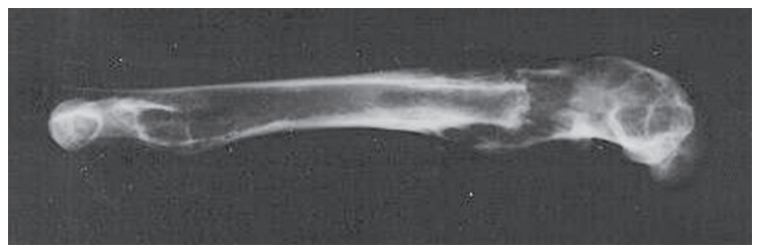

(b)

Figura 2. Radiografias dos ossos com 12 semanas de implante, a) controle Fio de "Steinmann"; e b) blenda 40/60.

Após 12 semanas de implante, notou-se que os calos ósseos apresentaram uma diminuição na sua dimensão principalmente no grupo polímero (Figura 2). Com 24 semanas de implante os calos ósseos apresentaram-se bem formados nos dois grupos (Figura 3).

\section{Observação microscópica}

A análise microscópica dos calos ósseos formados com o implante do fio de Steinmann (controle) e com o implante do polímero PLLA/PHBV 40/60 não apresentou diferenças significativas. Com 6 semanas de implante, tanto do controle quanto do polímero, ainda era observado tecido cartilaginoso indicando processo de consolidação por ossificação endocondral (Figura 4).

Após 12 semanas de implante não foi encontrada a presença de tecido cartilaginoso indicando assim que houve substituição integral do tecido cartilaginoso por tecido ósseo (Figura 5).

A análise histológica após 24 semanas mostrou que o tecido ósseo do calo apresenta uma consolidação mais evidente. Os osteócitos estão em arranjos paralelos, porém com

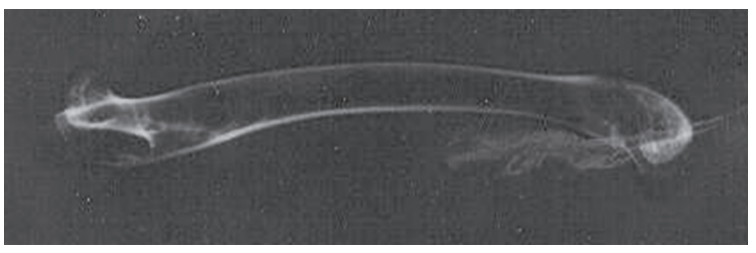

(a)

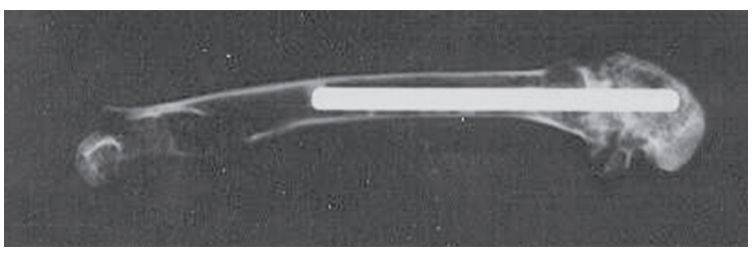

(b)

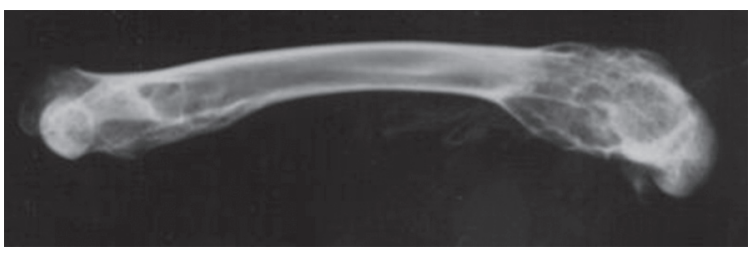

(c)

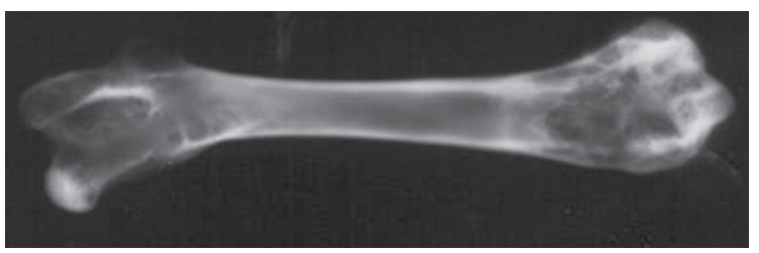

(d)

Figura 3. Radiografias dos ossos com 24 semanas de implante, a) osso virgem; b) controle Fio de "Steinmann"; c) e d) blenda PLLA/PHBV 40/60, vista de perfil e superior.

poucos sistemas de Havers (ósteons) completamente formados (Figura 6).

Foi possível observar formação de calo ósseo em todos os casos. Notou-se a formação de um osso periostal menos compacto e que a arquitetura do osso em formação não mostrou diferenças entre o implante e o controle.

Através da análise histológica dos calos ósseos formados no grupo polímero e no grupo controle, foi possível verificar que o polímero não influenciou negativamente na formação do tecido ósseo, quando comparado com o fio de Steinmann, já utilizado comercialmente. Isto demonstra que o polímero PLLA/PHBV 40/60 apresenta boas propriedades para fixação de fraturas.

O uso de implantes poliméricos na forma de placas fixadas com parafusos apresenta algumas desvantagens, dentre elas o fato da degradação aumentar o orifício por onde passa o parafuso, causando microfraturas nos parafusos devido ao esforço de cisalhamento e resultando em falha da fixação ${ }^{[20]}$. Esses problemas podem ser eliminados com o uso de suturas para a fixação do implante ou com o uso de um implante intramedular ${ }^{[20]}$.

As complicações mais freqüentes descritas em associação ao uso de implantes absorvíveis são a ocorrência de reações in- 


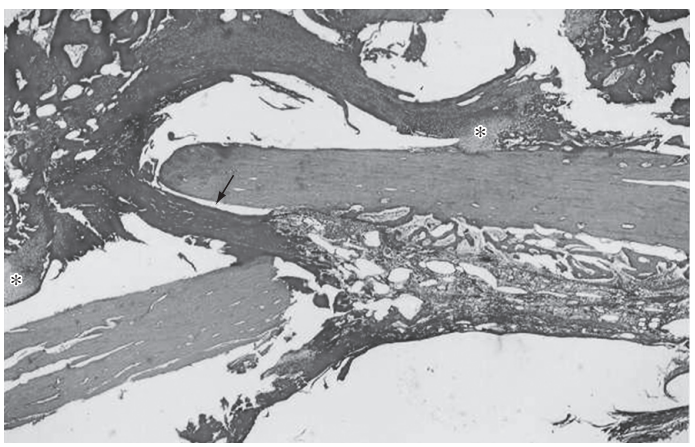

(a)

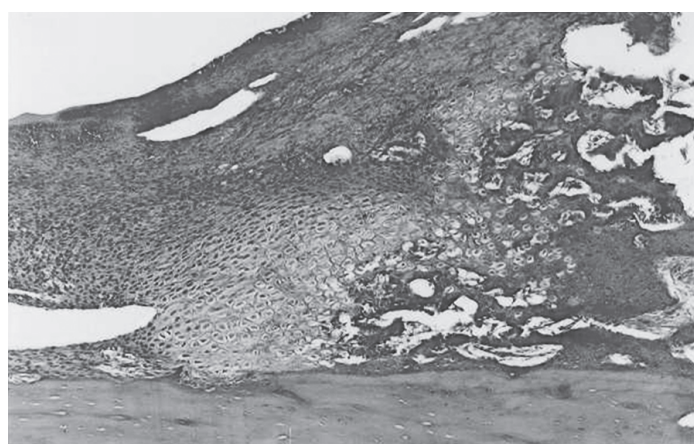

(b)

Figura 4. Fotomicrografia do calo ósseo após 6 semanas de implante do fio de Steinman (controle), a) mostrando o osso fraturado e invasão tecidual de tecido conjuntivo derivado do periósteo (seta). Notar a presença de cartilagem hialina próximo ao osso fraturado (*). HE 12,5x. b) Detalhe da região de cartilagem hialina mostrando o processo de ossificação endocondral. HE 62,5x.

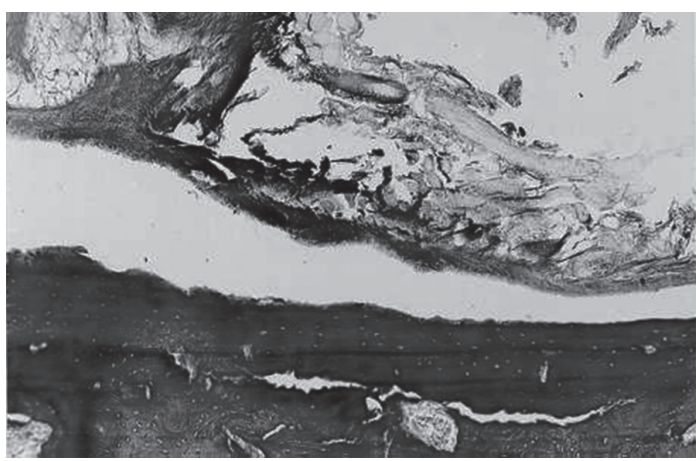

(a)

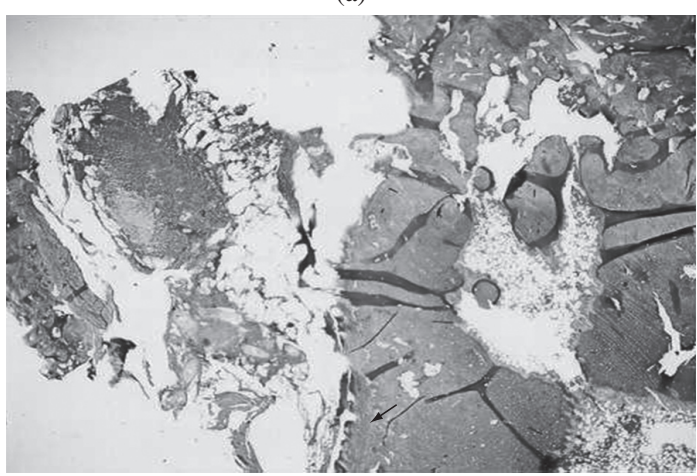

(b)

Figura 5. Fotomicrografia do calo ósseo após 12 semanas de implante: a) fio de Steinman (controle) (HE 62,5x); e b) implante da blenda PLLA/PHBV $40 / 60$. Nota-se a presença de formação de tecido ósseo mais organizado (sistema circunferencial externo) (seta) (HE 12,5x).

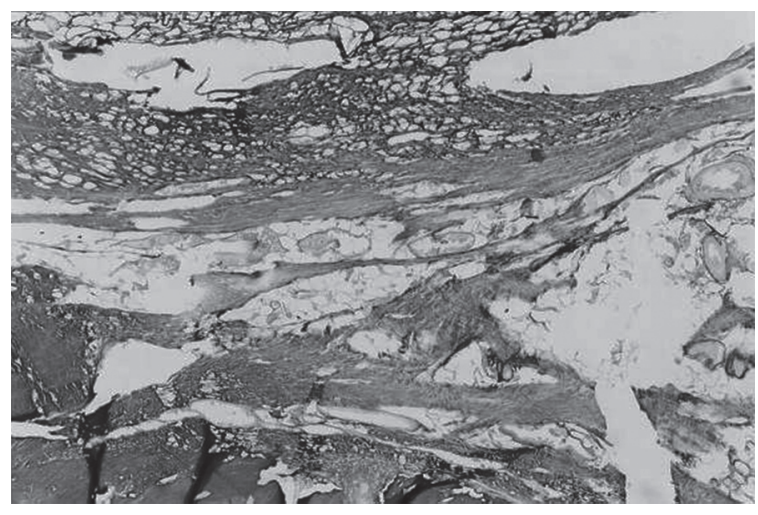

(a)

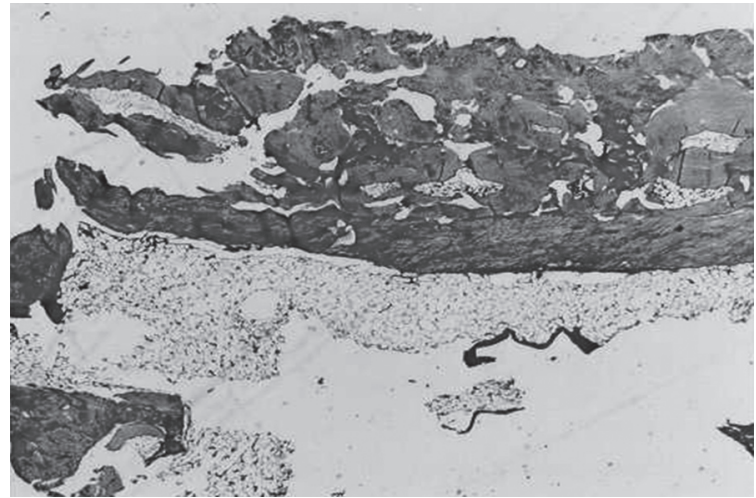

(b)

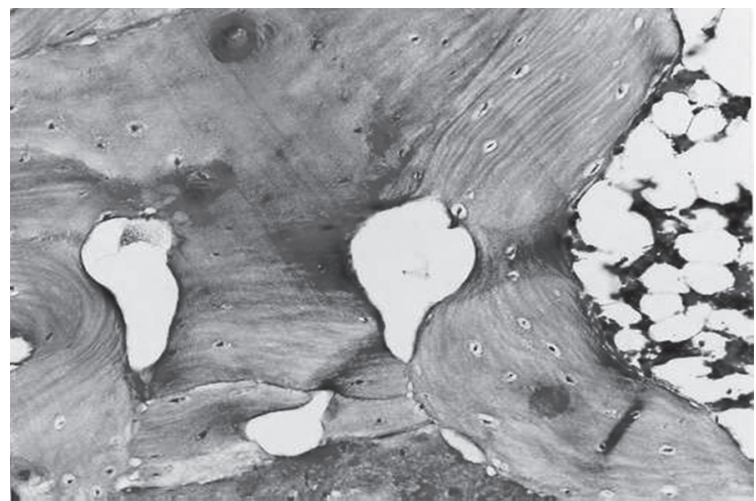

(c)

Figura 6. Fotomicrografia do calo ósseo após 24 semanas de implante, ilustrando uma vista panorâmica de: a) fio de Steinman (controle) (HE 62,5x); b) blenda PLLA/PHBV 40/60, mostrando a formação óssea mais pronunciada (HE 12,5x); e c) região do implante da blenda mostrando em detalhe a disposição dos osteócitos em arranjo paralelo sem a formação de ósteons (HE 125x).

flamatórias e de osteólise. Segundo Kfuri e colaboradores estas complicações apresentam uma incidência no uso clínico em humanos de até $10 \%$ dos $\operatorname{casos}^{[10]}$. Ainda segundo Kfuri e colaboradores, esses efeitos adversos podem estar relacionados à rápida metabolização dos polímeros e a sua ocorrência não parece interferir com o resultado final do tratamento ${ }^{[10]}$. Neste trabalho não se detectou a ocorrência de reações inflamatórias ou osteólise após o implante do polímero, nem do controle. 


\section{Ensaio Mecânico}

A Tabela 1 mostra as mudanças nas propriedades mecânicas dos ossos com o implante PLLA/PHBV 40/60 e com o controle de fio de Steinmann. Podemos observar que o módulo de Young (E) aumentou com o tempo de implante tanto para o osso com a haste polimérica, como para o controle. O mesmo ocorre com a tensão máxima no escoamento para ambos os tipos de implante. Nota-se que o aumento nas propriedades mecânicas para o osso implantado com o polímero ocorreu de forma mais lenta que o osso implantado com o metal. Observou-se que, em 24 semanas, ambos ainda se encontravam abaixo do valor obtido para o osso virgem. Esse fato pode ser parcialmente decorrente do método pouco preciso utilizado para determinar a área da superfície dos ossos em cada amostra, onde a remodelagem cortical ocorreu ao longo do calo ósseo externo ao osso, e a seção transversal do osso invariavelmente incluiu alguns tecidos moles. Simultaneamente ao aumento dos valores da área superficial ocorreu decréscimo dos resultados obtidos de módulo de Young e da tensão máxima no escoamento, para os ossos implantados ${ }^{[12]}$. Isso também pode explicar o fato das propriedades mecânicas dos ossos implantados com o polímero terem sido inferiores aos ossos implantados com o fio de Steinmann. Observouse que em sua maioria, os calos ósseos formados nos ossos implantados com o polímero, encontravam-se discretamente maiores que os calos formados no grupo controle.

A Tabela 2 mostra os dados obtidos através do ensaio mecânico da haste polimérica durante a degradação in vivo. Observa-se uma queda nos valores do módulo de Young e tensão máxima no escoamento, mostrando a degradação do

Tabela 1. Valores de módulo de Young (E) e tensão máxima no escoamento obtidos pelo ensaio mecânico no módulo flexão para os ossos em diferentes tempos de implante, com a blenda 40/60 PLLA/PHBV e com controle fio de Steinmann.

\begin{tabular}{ccccc}
\hline & \multicolumn{2}{c}{$\begin{array}{c}\text { Módulo de Young } \\
(\mathbf{E})(\mathbf{M P a})\end{array}$} & \multicolumn{2}{c}{$\begin{array}{c}\text { Tensão máxima no } \\
\text { escoamento (MPa) }\end{array}$} \\
\cline { 2 - 5 } & \multicolumn{2}{c}{ Desvio padrão } & \multicolumn{2}{c}{ Desvio padrão } \\
\hline Implante 6 sem & 61,3 & 18,4 & 3,86 & 1,57 \\
Implante 12 sem & 206,14 & 151,05 & 7,96 & 5,56 \\
Implante 24 sem & 722,07 & 459,17 & 18,03 & 8,93 \\
Controle 6 sem & 254,16 & 144,59 & 10,73 & 5,57 \\
Controle 12 sem & 961,87 & 776,11 & 13,19 & 7,65 \\
Controle 24 sem & 1655,15 & 909,66 & 25,95 & 9,03 \\
Osso virgem & 2847,98 & 838,48 & 45,35 & 11,27 \\
\hline
\end{tabular}

Tabela 2. Valores de módulo de Young (E) e tensão máxima no escoamento obtidos pelo ensaio mecânico no módulo flexão para os implantes da blenda PLLA/PHBV 40/60 em diferentes tempos de degradação in vivo.

\begin{tabular}{ccccc}
\hline $\begin{array}{c}\text { PLLA/ } \\
\text { PHBV }\end{array}$ & \multicolumn{2}{c}{$\begin{array}{c}\text { Módulo de Young (E) } \\
\text { (MPa) }\end{array}$} & \multicolumn{2}{c}{$\begin{array}{c}\text { Tensão máxima no } \\
\text { escoamento (MPa) }\end{array}$} \\
\hline $\mathbf{4 0 / 6 0}$ & \multicolumn{2}{c}{ Desvio padrão } & \multicolumn{2}{c}{ Desvio padrão } \\
\hline 0 sem & 2120,00 & 200,00 & 87,00 & 8,10 \\
6 sem & 2058,17 & 696,19 & 36,57 & 3,86 \\
12 sem & 1725,08 & 526,52 & 24,25 & 5,21 \\
24 sem & 1321,52 & 568,84 & 18,27 & 4,91 \\
\hline
\end{tabular}

polímero com o tempo de implante in vivo. Como verificado no estudo in vitro e in vivo (através das análises térmicas), a mistura polimérica demonstrou um aumento no grau de cristalinidade durante a degradação, tendo como consequiência perda nas propriedades mecânicas ${ }^{[17,18]}$.

Os altos valores de desvio padrão obtidos para as propriedades mecânicas pode ser devido ao fato do osso ser constituído de material anisotrópico e sem uniformidade geométrica. Para amenizar este fato, seria necessário preparar corpos de prova, mas com isso perderia-se a interação entre os diversos componentes microestruturais existentes ao longo do osso.

Burstein e Frankel demonstraram que a grande variabilidade das tensões nas propriedades de rigidez e energia absorvida pelos ossos pode ser produzida pelo fator velocidade nos ensaios. Temos como exemplo o caso das tíbias humanas que podem absorver $45 \%$ mais energia quando fraturadas a taxas de deformação equivalentes ao trauma, quando comparados com ensaios onde são utilizadas baixas velocidades de aplicação de carga ${ }^{[21]}$.

\section{Análise de microscopia eletrônica de varredura (SEM)}

Na Figura 7 pode-se observar micrografia obtida por SEM da blenda de PLLA/PHBV (40/60) antes e após 12 semanas de degradação in vivo. Nota-se que inicialmente a haste apresenta um corpo compacto sem porosidade e nem fraturas internas. Após a degradação observa-se a presença de fraturas

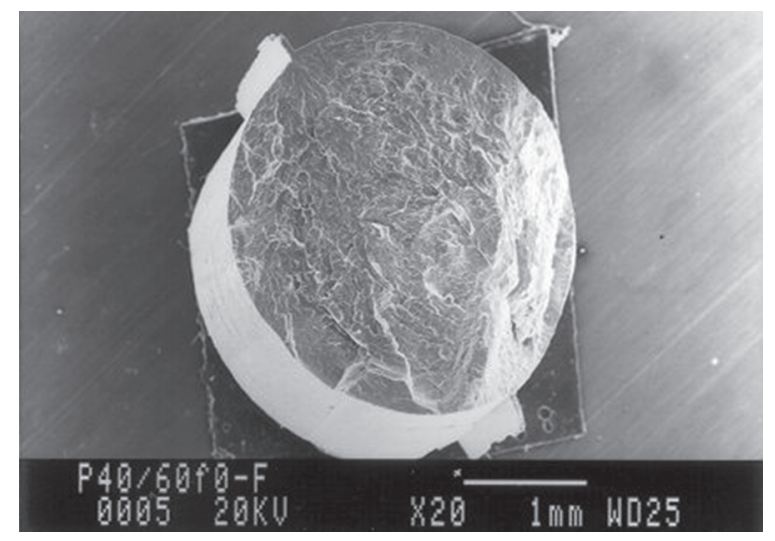

(a)

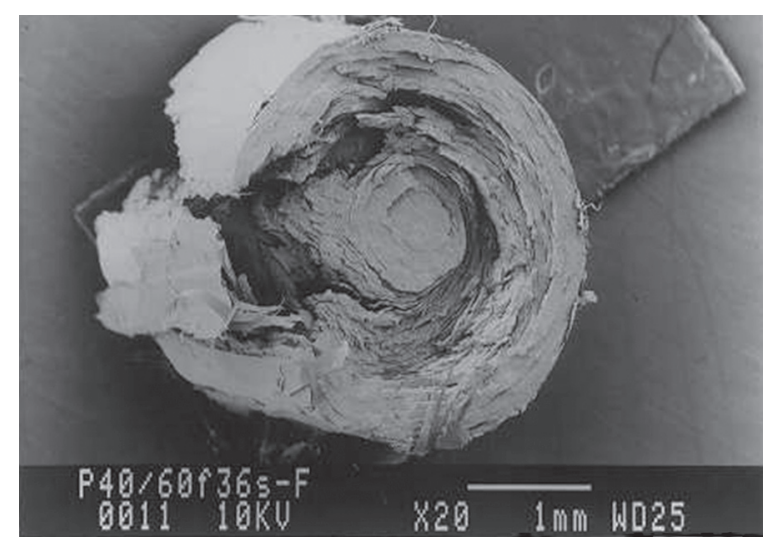

(b)

Figura 7. Fotomicrografias da blenda PLLA/PHBV 40/60, onde a) sem degradação; e b) com 12 semanas de degradação in vivo. 
internas na forma de camadas até no centro do material, o que comprova que a blenda PLLA/PHBV (40/60) sofre degradação com fluidos corpóreos ${ }^{[17,18]}$.

Cabe aqui salientar que Ferreira e colaboradores (2005) mostraram que a blenda PLLA/PHBV sofre degradação hidrolítica também na forma de camadas, tornando-se um material fortemente degradado em 52 semanas $^{[17]}$.

\section{Análise por calorimetria diferencial de varredura modular (MDSC)}

A Figura 8 mostra as curvas obtidas através do MDSC e os dados encontram-se na Tabela 3. No primeiro aquecimento (Figura 8a) nota-se a formação de um pico de cristalização em torno de $80^{\circ} \mathrm{C}$, referente à cristalização do PLLA, não existente na blenda não degradada. Este pico de cristalização pode estar relacionado à degradação do PLLA, formando novos cristais. Este mesmo pico desaparece após 24 semanas mostrando que o PLLA apresenta-se muito degradado e com a presença do PHBV na blenda, não havendo mais possibilidade do PLLA cristalizar. Como verificado em estudos anteriores in vitro ${ }^{[17,18]}$, o PLLA degrada mais rapidamente que o PHBV. Por outro lado, no segundo aquecimento, observou-se uma alteração no pico de cristalização referente ao PHBV (Figura 8b), iniciando uma pequena divisão e aproximação dos picos de cristalização do PLLA e do PHBV com 12 semanas, como observado no estudo in vitro. Após 24 semanas de implantação já não há mais separação dos dois picos de cristalização dos dois polímeros e sim a presença de um só pico em torno de $62^{\circ} \mathrm{C}$. Os autores acreditam que esteja ocorrendo um rearranjo dos cristais, devido ao fato da degradação do PLLA estar elevando a temperatura de cristalização do PHBV, aproximando os picos de cristalização dos polímeros. Este fato também já foi discutido por Penning e colaboradores ${ }^{[22]}$, onde os autores sugerem a ocorrência de co-cristalização do sistema.

A temperatura de fusão dos dois polímeros não sofreu alteração com a degradação, mas a entalpia de fusão $(\Delta \mathrm{Hm})$ do PLLA diminuiu com o tempo de implante (Tabela 3). Com 24 semanas de implante o $\Delta \mathrm{Hm}$ não foi observado mais no primeiro aquecimento (Figura 8a) e no segundo aquecimento (Figura 8b) notou-se apenas um pequeno pico.

Como pode ser observado, a degradação da blenda in vivo foi mais rápida que in vitro, comparado com estudo anterior de

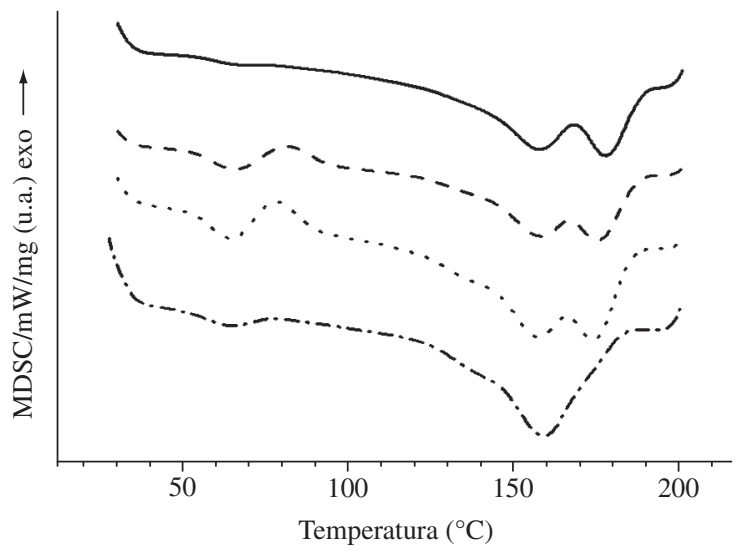

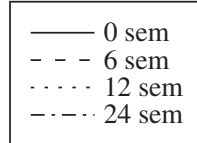

(a)
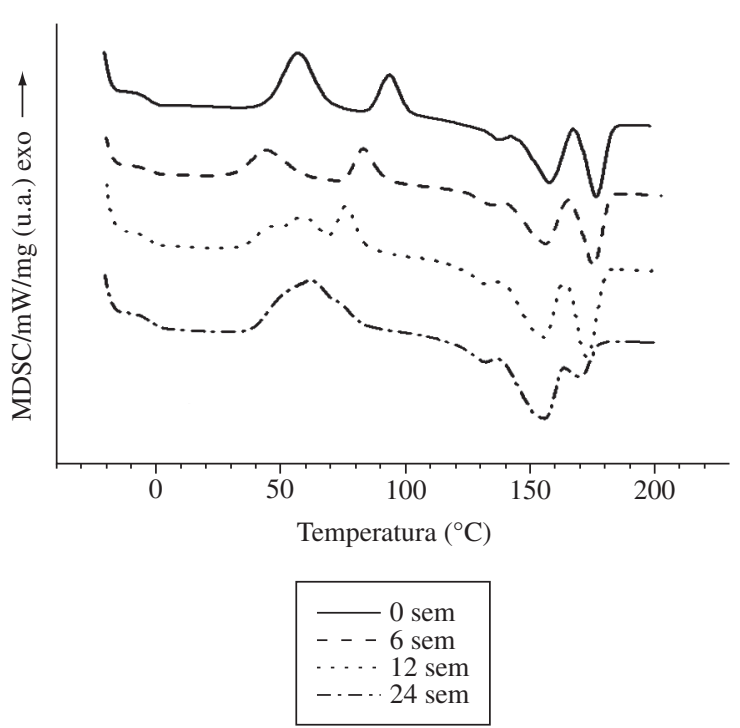

(b)

Figura 8. Curvas de MDSC obtidas para os pinos de PLLA/PHBV 40/60, em diferentes tempos de degradação in vivo ( $0,6,12$ e 24 semanas). Onde: a) primeiro aquecimento; e b) segundo aquecimento.

Tabela 3. Temperaturas de transição vítrea (Tg), cristalização (Tc) e fusão (Tm), entalpias de cristalização ( $\Delta \mathrm{Hc})$ e de fusão $(\Delta \mathrm{Hm})$, e grau de cristalinidade $(\chi)$ obtidos por MDSC, para a blenda PLLA/PHBV 40/60 em diferentes tempos de degradação in vivo.

\begin{tabular}{|c|c|c|c|c|c|c|c|c|c|c|c|c|}
\hline \multicolumn{2}{|c|}{ MDSC } & \multicolumn{2}{|c|}{$\operatorname{Tg}\left({ }^{\circ} \mathrm{C}\right)$} & \multicolumn{2}{|c|}{ Te $\left({ }^{\circ} \mathrm{C}\right)$} & \multicolumn{2}{|c|}{$\Delta \mathbf{H c}\left({\mathrm{J} . g^{-1}}^{-1}\right)$} & \multicolumn{2}{|c|}{$\operatorname{Tm}\left({ }^{\circ} \mathbf{C}\right)$} & \multicolumn{2}{|c|}{$\Delta \mathrm{Hm}\left(\mathrm{J.g}^{-1}\right)$} & \multirow{2}{*}{$\begin{array}{l}\chi(\%) \\
\text { PLLA }\end{array}$} \\
\hline PLLA/PHBV & Aquec. & PHBV & PLLA & PHBV & PLLA & PHBV & PLLA & PHBV & PLLA & PHBV & PLLA & \\
\hline \multirow[t]{2}{*}{$0 \mathrm{sem}$} & $1^{\circ}$ & - & 60 & - & - & - & - & 156 & 178 & 11 & 9 & 24 \\
\hline & $2^{\circ}$ & -2 & - & 57 & 93 & 25 & 10 & $137-157$ & 176 & 25 & 16 & - \\
\hline \multirow[t]{2}{*}{6 sem } & $1^{\mathrm{o}}$ & - & 58 & - & 82 & - & 5 & 156 & 176 & 7 & 8 & 8 \\
\hline & $2^{\circ}$ & -3 & - & 44 & 83 & 15 & 10 & $133-156$ & 175 & 26 & 19 & - \\
\hline \multirow[t]{2}{*}{$12 \mathrm{sem}$} & $1^{\mathrm{o}}$ & - & 58 & - & 78 & - & 6 & 156 & 175 & 8 & 8 & 5 \\
\hline & $2^{\circ}$ & -3 & - & $45-58$ & 76 & 11 & 6 & $131-155$ & 172 & 24 & 17 & - \\
\hline \multirow[t]{2}{*}{24 sem } & $1^{\circ}$ & - & 57 & - & 77 & - & 1 & 159 & - & 53 & - & - \\
\hline & $2^{\circ}$ & -2 & - & 62 & - & 39 & - & $131-155$ & 170 & 26 & 4 & - \\
\hline
\end{tabular}


Ferreira e colaboradores ${ }^{[17,18]}$, que com 36 semanas de degradação in vitro ainda era possível observar nitidamente a entalpia de fusão $(\Delta \mathrm{Hm})$ do PLLA. Essa degradação mais rápida in vivo pode ser devido à influência dos fluidos corpóreos e do esforço mecânico na região do implante acelerando a degradação da mesma. Comprovando a necessidade de trabalhar com a blenda 40/60.

\section{Conclusões}

As análises histológica e radiológica demonstraram a formação de calo ósseo e que não há diferenças entre os calos formados no grupo polímero e no grupo controle. O ensaio mecânico mostrou que a consolidação óssea estava ocorrendo de forma satisfatória para ambos os grupos. As análises de MDSC e ensaio mecânico mostraram que ocorre a degradação da haste PLLA/PHBV 40/60 no tempo estudado, ou seja, até 24 semanas.

Com os dados obtidos nesse estudo, podemos afirmar que a mistura polimérica PLLA/PHBV 40/60 mostrou ser promissora no campo de reparação de fraturas ósseas, devido ao seu bom desempenho comparado com o controle de fio de Steinmann. Por outro lado, a haste de polímero apresenta a vantagem de eliminar uma segunda cirurgia para retirada do implante após a consolidação da fratura, já que a mesma é degradada e absorvida pelo organismo.

O estudo dos polímeros bioreabsorvíveis apresenta horizonte bastante amplo, uma vez que é possível trabalhar a estrutura molecular, obtendo-se copolímeros, bem como realizar novas misturas destes biomateriais visando alterar as suas propriedades. Com isso, um mesmo polímero pode ser produzido com a rigidez necessária para compor um dispositivo de osteossíntese ou com a porosidade exigida para obter membranas coadjuvantes do preenchimento de falhas ósseas.

\section{Agradecimentos}

Os autores gostariam de agradecer à FAPESP (processo 97/06268-0 e 97/14275-7), e ao FINEP/PRONEX pelo apoio financeiro.

\section{Referências Bibliográficas}

1. Yuehuei, H. A.; Shane, K. W. \& Friedman, R. J. - Biomaterials, 21, p.2635 (2000).

2. Duek, E. A. R.; Zavaglia, C. A. C. \& Belangero, W. D. Polymer, 40, p.6465 (1999).
3. Pezzin, A. P. T. "Obtenção, caracterização de blendas de Poli(para-dioxanona)/Poli(L-ácido láctico) (PPD/PLLA) para aplicação como prótese de menisco bioreabsorvível', Tese de Doutorado, Universidade Estadual de Campinas, Brasil (2001).

4. Barbanti, S. H.; Zavaglia, C. A. C. \& Duek, E. A. R. Acta Microscópica, 9, (A), p.17 (2000).

5. Luciano, R. M.; Zavaglia, C. A. C. \& Duek, E. A. R. Artificial Organs, 24, p.206 (2000).

6. Seal, B. L.; Otero, T. C. \& Panithc, A. - Materials Science and Engeneering R, 34, p.147 (2001).

7. Yang, J.; Bei, J \& Wang, S. - Biomaterials, 23, p.2607 (2002).

8. Köse, G. T. et al. - "Journal of Materials Science: Materials in Medicine”, 14, p.121 (2003).

9. Lotti, N. et al. - Polymer, 34, p.4935 (1993).

10. Kfuri, M. Jr.; Paccola, C. J.; Chierice, G. O. \& Shimano, A.C. - Revista Brasileira de Ortopedia, 36, (4), p.? (2001).

11. Van der Elst, M. et al. - Journal of Biomedical Materials Research, 30, p.139 (1996).

12. Manninen, J. M. \& Pohjonen, T. - Biomaterials, 14, p.305 (1993).

13. Lu, L. et al. - Biomaterials, 21, p.1837 (2000).

14. Mendes, S. et al. - Biomaterials, 22, p.2057 (2001).

15. Grimaldi, M. et al. - "Journal of Materials Science”, 31, p.6155 (1996).

16. Piattelli, A. et al. - Biomaterials, 17, p.791 (1996).

17. Ferreira, B. M. P. \& Duek, E. A. R. - “Journal of Applied Biomaterials Biomechanics”, 3, p.50 (2005).

18. Ferreira, B. M. P.; Zavaglia, C.A.C. \& Duek, E. A. R. Materials Research, 4, (1), p.34 (2001).

19. Hebert, S. et al. - "Ortopedia e traumatologia: princípios e prática”, ArtMed, Porto Alegre (1998).

20. Vainionpää, S. et al. - Acta Orthop. Scand. 57, p.237 (1986).

21. Burstein, A. H. \& Frankel. A - Journal Biomechanics, 21, p.155 (1971).

22. Penning, J. P. \& Manley, R. St. J. - Macromolecules, 29, p.84 (1996).

Enviado: 13/06/07

Reenviado: 03/04/08

Aceito: $10 / 06 / 08$ 